\title{
Assessment of Knowledge, Attitude and Practice among Hypertensive Patients in a Teaching Hospital
}

\author{
Sheena Marin Thomas ${ }^{1, *}$, Suma Varghese ${ }^{2}$, Bincy Raj ${ }^{3}$ \\ 'Department of Pharmacy Practice, College of Pharmaceutical Sciences, Dayananda Sagar University, Bangalore, Karnataka, INDIA \\ 2Department of Pharmaceutics, College of Pharmaceutical Sciences, Dayananda Sagar University, Bangalore, Karnataka, INDIA. \\ ${ }^{3}$ Department of Pharmacognosy, College of Pharmaceutical Sciences, Dayananda Sagar University, Bangalore, Karnataka, INDIA.
}

\begin{abstract}
Objectives: To assess knowledge attitude and practice regarding hypertension and secondary objective was to improve the health related quality of life by means of patient counselling. Methods: It was a prospective interventional study which was carried out for six months. Patient's demographic details like were collected in a pre-designed data entry form. KAP questionnaire was used to assess patient's knowledge, attitude and practice components before and after giving counselling session. SPSS18.0 was the statistical software used to analyses the data. Results: In a total of 120 male patients were $(51.7 \%)$ and belong to the age group of $41-60$ years. In this study, the pre-counselling KAP was assessed in which 30(25\%), 60(50\%) and $69(57.5 \%)$ patients had good score of knowledge, attitude and practice of Hypertension whereas the post counselling KAP showed that 103(85.83\%), $116(96.66 \%)$ and $117(97.5 \%)$ score respectively. It shows that the patient counselling has a great impact on quality of life. Conclusion: It has been observed that hypertension affects the health of patients and education
\end{abstract}

has a major role in improving the health care outcomes. This study concluded that before giving counselling session participants had inadequate information regarding complications of disease which led to worsening of health conditions. After giving intervention these patients showed marked improvement in quality of life.

Key words: Hypertension, Patient counseling, KAP Questionnaire, Brochures, Quality of Life.

\section{Correspondence}

Mrs: Sheena Marin Thomas,

Assistant Professor, Department of Pharmacy Practice, College of Pharmaceutical Sciences, Dayananda Sagar University, Bangalore-560078, Karnataka, INDIA.

Email id: sheenathomas-sps@dsu.edu.in

DOI: 10.5530/jyp.2021.13.57

\section{INTRODUCTION}

Among the different disease conditions hypertension is considered as an important factor which leads to severe burden of diseases in South Asia. ${ }^{1}$ It has become a global challenge and is ranked third as the cause of disability adjusted life years. ${ }^{2}$ Around $57 \%$ of all stroked and $24 \%$ of all the Coronary heart disease deaths in India are caused due to its complications. ${ }^{3}$ According to the data by World Health Organization (WHO), the most important cause of premature deaths worldwide is hypertension. ${ }^{4}$ While carrying out an analysis of population health data for Attributable deaths and attributable disease burden in the Global and Regional Burden of Disease and Risk Factors study it was found that hypertension in South Asia was rank second only to child underweight for age. ${ }^{5}$ It's a chronic condition where several barriers exists for its control such as physicians turn over, not following guidelines properly, selecting two or more antihypertensive drugs from same category, side effects due to usage of multiple drugs and not following a single physician. ${ }^{6}$ However the results from a multicenter study in India on awareness, treatment and adequacy of control of hypertension (HTN) showed that only $25.6 \%$ of hypertensive undergoing treatment were successful in keeping their blood pressure under control. ${ }^{7}$ Hypertension is defined as a systolic blood pressure(SBP) above $140 \mathrm{mmHg}$ and/or a diastolic blood pressure (DBP) above $90 \mathrm{~mm} \mathrm{Hg.}{ }^{8}$

Hypertension is always considered as silent killer as it presents with no warning signs. Majority people don't experience any symptoms but few manifest symptoms like dull headaches, vomiting, dizzy spells and frequent nose bleeds. ${ }^{9}$ Blood pressure is classified into one of four categories normal, pre- hypertension, stage land stage $2 \mathrm{HTN}$ based on the Eighth report of the Joint National Committee (JNC-8). ${ }^{10}$ Pre-hypertension in itself is not a disease but is like a warning sign and identifies those who are likely to develop stage 1 and stage $2 \mathrm{HTN} .{ }^{11}$ High blood Pressure can also cause damaging effects to the brain specifically it can cause aneurysm or stroke. ${ }^{12}$

Significant changes have been noted in the incidence and prevalence of hypertension where major dietary changes had been implemented. Even though antihypertensive drugs are having greater impact on blood pressure control but nowadays more importance and emphasis were given on management of complications by lifestyle modifications. ${ }^{13}$ According to the $7^{\text {th }}$ report of Joint National Committee few life style modifications have been recommended on prevention, detection, evaluation and treatment of high blood pressure as follows:-

\begin{tabular}{|c|c|c|}
\hline Modifications & Recommendations & $\begin{array}{l}\text { Avg, sbp, } \\
\text { reduction range }\end{array}$ \\
\hline $\begin{array}{l}\text { Weight } \\
\text { reduction }\end{array}$ & $\begin{array}{l}\text { Maintain normal body weight [BMI } \\
\left.\qquad 18.5-24.9 \mathrm{~kg} / \mathrm{m}^{2}\right]\end{array}$ & $5-20 \mathrm{mmHg} / 10 \mathrm{~kg}$ \\
\hline DASH Therapy & $\begin{array}{l}\text { Minimise the quantity of saturated } \\
\text { fat and should consume food rich in } \\
\text { low fat dairy products }\end{array}$ & 8-14 mmHg \\
\hline $\begin{array}{l}\text { Dietary sodium } \\
\text { reduction }\end{array}$ & $\begin{array}{l}\text { Minimise dietary Sodium } \\
\text { consumption to } 6 \mathrm{~g} \text { Sodium }\end{array}$ & $2-8 \mathrm{mmHg}$ \\
\hline $\begin{array}{l}\text { Aerobic physical } \\
\text { activity }\end{array}$ & $\begin{array}{l}\text { Daily aerobic physical activity for } \\
\text { atleast half an hour per day }\end{array}$ & 4-9 mmHg \\
\hline Moderation & Men: limit to $<2$ drinks per day & $2-4 \mathrm{mmHg}$ \\
\hline $\begin{array}{l}\text { of alcohol } \\
\text { consumption }\end{array}$ & $\begin{array}{l}\text { Women and lighter weight persons: } \\
\text { limit to }<1 \text { drink per day }\end{array}$ & \\
\hline
\end{tabular}

${ }^{*} 1$ drink $=1 / 2$ oz or $15 \mathrm{ml}$ ethanol [e.g., $12 \mathrm{oz}$ beer, $5 \mathrm{oz}$ wine, $1.5 \mathrm{oz} 80$-proof whiskey].

This is an open access article distributed under the terms of the Creative Commons Attribution-NonCommercial-ShareAlike 4.0 License, which allows others to remix, tweak, and build upon the work non-commercially, as long as the author is credited and the new creations are licensed under the identical terms. 
From Randomized Controlled Trials (RCT), abundant evidences are there which shows the benefits of antihypertensive drug in reducing the important health outcomes in persons with hypertension. ${ }^{14}$ The choice of initial therapy varies, depending upon the patient's condition, age, co-morbidities etc. ${ }^{15}$ Usually monotherapy is considered as the standard initial treatment for hypertension and the dose is gradually increased when the desired goal is not achieved. ${ }^{16}$ Based on the cause and different pathogenesis of Hypertension, patients usually require multiple antihypertensives drugs to obtain proper control of blood pressure. ${ }^{17}$

Most of the antihypertensive agents produce dose dependent side effects such as hypotension, dizziness, headache, nausea, vomiting, diarrhea or constipation, skin rash etc. ${ }^{18}$ Excessive reduction in BP, increased incidence of side effects and difficulty in determining the drug responsible for a particular side effect are few of the disadvantages associated with the use of combination therapy as the initial treatment for hypertension. ${ }^{19}$

Knowledge, Attitude and Practice (KAP) Questionnaire is mainly used to understand people's perception about certain things, their feelings and behavior towards disease mangement. ${ }^{20}$ It includes awareness regarding medication names, lifestyle interventions, physical activity etc. To develop compliance with medications, its very essential to have good knowledge about disease and medications. ${ }^{21}$

Low health literacy compromises these if management abilities of the elderly patients such as using basic health related materials, like prescriptions, pamphlets, articles, medication and food labels and health insurance plans, which ultimately had an effect on their ability to take appropriate and timely health care action. ${ }^{22}$

This study was mainly designed and conducted with the aim of assessing knowledge attitude and practice regarding hypertension in patients and to provide patient counselling by means of brochures. Thus, to improve the health-related quality of life in hypertensive patients.

\section{METHODS}

All the participants were given detailed explanation regarding the study and questionnaire in local language by means of informed consent form. The study was approved by the Institutional Ethics Committee of the Oxford Medical College, Attibele, Bangalore.

\section{Study Design and Data Collection}

It's a prospective interventional study carried out in General Medicine Department for a duration of 6 months. Inclusion criteria consisted of patients of both genders above 18 years diagnosed with hypertension and those who were willing to participate and able to communicate. Specially designed data collection form was made to collect demographics of the patients such as age, gender, socioeconomic status, past medical and medication history and relevant laboratory details. Patients who cannot read and write and those hypertensive patients admitted in ICU were excluded.

\section{Data Analysis}

Initially consent was obtained from participants by means of informed consent form. Demographics of the patients and data regarding past medical and medication history, diagnosis and details of prescribed drugs were collected. Assessment of Knowledge, Attitude and Practice among hypertensive patients was evaluated by administering KAP Questionnaire. The KAP questionnaire (in English and Kannada) consisted of 21 questions which were divided into three parts such as knowledge attitude and practice and is shown in Appendix -1.

The KAP scoring was as follows:

Total score: $0-3=$ POOR, 4-7 = GOOD
Based on the scores counselling was given related to life style modifications. Same set of patients were reassessed by administering the questionnaire again.

\section{Statistical Analysis}

Descriptive and inferential statistical analysis has been carried out in this study. Data's were mentioned in mean (SD) values and categorical variables were presented in percentage. Paired $T$ test has been used to find out significance of proportion in paired data. Microsoft word and excel were used to generate graphs and tables. Statistical software known as SPSS 18.0 and $\mathrm{R}$ environment ver 3.2.2 were used to find out the $\mathrm{p}$ value.

\section{RESULTS}

\section{Patient Characteristics}

A total of 120 hypertensive patients were enrolled in the study from General Medicine Department of The Oxford Medical College, Hospital and Research Centre, Bengaluru. Patients were recruited in the study based on inclusion criteria. The majority $57(47.5 \%)$ patients were diagnosed with hypertension alone whereas 18 (15\%) were having Hypertension and Diabetes and 45 (37.5\%) were having other comorbid conditions. (Table 1)

Out of 120 hypertensive patients 62 (51.7\%) were males and $58(48.3 \%)$ were females. The age of the patient ranged from 18-100 years with a mean (SD) of 55.14 (12.9) years. Majority 60 (50\%) of the patients were belonging to the age group of 41-60 years. On considering social habits $21.7 \%$ were smokers, $19.2 \%$ were alcoholics and $17.5 \%$ were taking tobacco. On considering social habits total smokers were $21.7 \%, 19.2 \%$ were alcoholics and $17.5 \%$ were taking tobacco. Based on the socioeconomic status almost 71 (59.2\%) were having medium status and 49 $(40.8 \%)$ were having poor status. According to blood pressure distribution of patient's majority (62\%) had systolic BP above 140 and (89\%) had diastolic BP between 80-100. Socio demographics and clinical characteristics of hypertensive patients are shown in Table 2.

Effect of patient counselling on knowledge related questions were studied and significance was found out in [Table 3]. Effect of patient counselling on attitude related questions and significance was found out in [Table 4]. Effect of patient counselling on practice related questions and its significance was found out in [Table 5]. Figure 1 shows the schematic presentation of study design and results.

\section{DISCUSSION}

Hypertension is a chronic condition where patients require better care and counselling to improve their quality of life. This study mainly focusses on the fact that how pharmacists by means of providing counselling can improve the different parameters such as knowledge regarding disease and its complications.

A prospective interventional study was carried out tlo assess the knowledge, attitude and practice among hypertensive patients for a period of six months at The Oxford Medical College, Hospital and Research Centre, Bangalore. The study included in-patients as well as out-patients treated in the General Medicine department who were suffering from hypertension. A total of 120 patients who fulfilled the inclusion criteria were included in the study out of which $62[51.7 \%]$ were male and 58[48.3\%] were female..$^{23,24}$

Our study showed that patient counselling have a greater impact on patients in improving health related outcomes. Initially due to lack of knowledge and awareness patients were not following medication regimen and diet therapy properly. Here post counselling KAP scores revealed that $103(85.83 \%), 116(96.6 \%)$ and 117 (97.5\%) patients had good score of knowledge, attitude and practice respectively. Several other 


\begin{tabular}{|c|c|c|}
\hline S. no & Questions & Answers \\
\hline 1 & How did you come to know about hypertension? & Clinical voluntary \\
\hline 2 & Do you have any relatives with history of hypertension? & Yes/No \\
\hline 3 & Do you know what the complications of hypertension are? & Yes/No \\
\hline 4 & Do you know normal level of blood pressure? & Yes/No \\
\hline 5 & Do you know the symptoms of hypertension? & Yes/No \\
\hline 6 & Do you think smoking and alcohol consumption cause hypertension? & Yes/No \\
\hline 7 & Do you think obesity is associated with hypertension? & Yes/No \\
\hline 8 & Do you know the names of your prescribed drugs? & Yes/No \\
\hline
\end{tabular}

TOTAL SCORE: $<3=$ Poor score; $>4=$ Good score ATTITUDE QUESTIONS (YES=1, NO=0)

\begin{tabular}{clc}
\hline S.no & \multicolumn{1}{c}{ Questions } & Answers \\
\hline 1 & Do you think regular medications will improve the disease & Yes/No \\
2 & Do you think only medications can control hypertension & Yes/No \\
3 & Do you think diet control will improve the condition & Yes/No \\
4 & Do you think salt reduction can control hypertension & Yes/No \\
5 & Do you think regular physical activity is essential & Yes/No \\
6 & Avoiding extra cooking oil & Yes/No \\
TOTAL SCORE: $<3=$ Poor score; $>4=$ Good score & \\
\hline PRACTICE RELATED QUESTIONS (YES=1, NO=0) & Questions \\
\hline S.no & & Answers \\
\hline 1 & Where you were first diagnosed with hypertension? & Yes/No \\
2 & Regular follow up & Yes/No \\
3 & Did you ever experience any side effect? & Yes/No \\
4 & Did you ever take double dose? & Yes/No \\
5 & Are you avoiding extra added salt? & Yes/No \\
6 & Are you doing any physical exercise daily? & Yes/No \\
7 & Are you taking your drugs regularly? & Yes/No \\
\hline
\end{tabular}

Table 1: Disease distribution in study population.

\begin{tabular}{ccc}
\hline Disesase Distribution & Number of Patients & Percentage (\%) \\
\hline Hypertension & 57 & 47.5 \\
Hypertension+ Diabetes & 18 & 15 \\
$\begin{array}{c}\text { Hyperetnsion with other } \\
\text { comorbid conditions }\end{array}$ & 45 & 37.5 \\
Total & 120 & 100 \\
\hline
\end{tabular}

studies showed positive impact of patient counselling on hypertensive patients. ${ }^{25,26}$

In our study patients having addictions of smoking and alcohol were less but it can be considered as an important risk factor for development of cardiovascular diseases in hypertensive patients. Many epidemiological studies from different parts of India have shown significant correlation of smoking and alcohol use with hypertension prevalence. ${ }^{27,28}$

In our study those participants who were having low socioeconomic status and physically inactive patients were having more risk of cardiovascular disease and mortality. The results obtained in this study were similar to earlier studies. ${ }^{29,30}$
Table 2: Socio demographics and clinical characteristics of Hypertensive patients.

\begin{tabular}{ccc}
\hline Variables & Number of patients $(\mathbf{n})$ & Percentage $(\%)$ \\
\hline & Gender & \\
Male & 58 & 48.3 \\
Female & 62 & 51.7 \\
& Age (Years) & 13.3 \\
$18-40$ & 16 & 50 \\
$41-60$ & 60 & 35 \\
$61-80$ & 42 & 1.6 \\
$81-100$ & 2 & 21.7 \\
& Social Habits & 19.2 \\
Smoking & 26 & 17.5 \\
Alcohol & 23 & 59.2 \\
Tobacco & 21 & 40.8 \\
Medium & Socio economic Status \\
Poor & 71 & \\
& 49 & 38.3 \\
120-140 & Blood Pressure Distribution \\
$>140$ & Systolic Blood Pressure \\
& 46 & 61.7 \\
$80-100$ & 74 & 88.3 \\
$>100$ & Diastolic Blood Pressure \\
\hline
\end{tabular}

Out of 120 patients before counselling the patients had poor knowledge, attitude and practice regarding hypertension. After giving patient counselling regarding lifestyle modifications and DASH therapy, these parameters were improved and quality of life in majority of patients. 
Table 3: Impact of patient counselling on Knowledge related questions ( $n=120)$.

\begin{tabular}{|c|c|c|c|c|}
\hline $\begin{array}{c}\text { Knowledge related } \\
\text { Questions }\end{array}$ & Pre-counselling & $\begin{array}{c}\text { Post } \\
\text { counselling }\end{array}$ & $\begin{array}{c}\% \\
\text { difference }\end{array}$ & $P$-value \\
\hline \multicolumn{5}{|c|}{ How did you come to know about hypertension? } \\
\hline Clinical & $116(96.7 \%)$ & $16(96.7 \%)$ & $0.0 \%$ & 0.500 \\
\hline Voluntary & $4(3.3 \%)$ & $4(3.3 \%)$ & $0.0 \%$ & \\
\hline \multicolumn{5}{|c|}{ Do you have any relatives with history of hypertension } \\
\hline Yes & $56(46.7 \%)$ & $64(53.3 \%)$ & $6.6 \%$ & 0.235 \\
\hline No & $64(53.3 \%)$ & $56(46.7 \%)$ & $-6.6 \%$ & \\
\hline \multicolumn{5}{|c|}{$\begin{array}{c}\text { Do you know what the complications of } \\
\text { hypertension are? }\end{array}$} \\
\hline Yes & $24(20 \%)$ & $68(56.7 \%)$ & $36.7 \%$ & $<0.001^{\star *}$ \\
\hline No & $96(80 \%)$ & $52(43.3 \%)$ & $-36.7 \%$ & \\
\hline \multicolumn{5}{|c|}{ Do you know the normal level of blood pressure? } \\
\hline Yes & $33(27.5 \%)$ & $85(70.8 \%)$ & $43.3 \%$ & $<0.001^{* *}$ \\
\hline No & $87(72.5 \%)$ & $35(29.2 \%)$ & $43.3 \%$ & \\
\hline \multicolumn{5}{|c|}{ Do you know the symptoms of HTN } \\
\hline Yes & $44(36.7 \%)$ & $106(88.3 \%)$ & $51.6 \%$ & $<0.001^{* *}$ \\
\hline No & $76(63.3 \%)$ & $14(11.7 \%)$ & $-51.6 \%$ & \\
\hline \multicolumn{5}{|c|}{ Do you think smoking and alcohol cause hypertension? } \\
\hline Yes & $44(36.7 \%)$ & $108(90 \%)$ & $53.3 \%$ & $<0.001^{* *}$ \\
\hline No & $76(63.3 \%)$ & $12(10 \%)$ & $-53.3 \%$ & \\
\hline \multicolumn{5}{|c|}{ Do you think obesity is associated with } \\
\hline \multicolumn{5}{|l|}{ hypertension? } \\
\hline Yes & $40(33.3 \%)$ & $114(95 \%)$ & $61.7 \%$ & $<0.001^{* *}$ \\
\hline No & $80(66.7 \%)$ & $6(5 \%)$ & $-61.7 \%$ & \\
\hline \multicolumn{5}{|c|}{ Do you know the names of your prescribed drugs? } \\
\hline Yes & $20(16.7 \%)$ & $56(46.7 \%)$ & $30.0 \%$ & $<0.001^{* *}$ \\
\hline No & $100(83.3 \%)$ & $64(53.3 \%)$ & $-30.0 \%$ & \\
\hline
\end{tabular}

Table 4: Impact of patient counselling on Attitude related questions ( $n=120)$.

\begin{tabular}{|c|c|c|c|c|}
\hline Attitude questions & Pre counseling & $\begin{array}{c}\text { Post } \\
\text { counseling }\end{array}$ & $\begin{array}{c}\% \\
\text { difference }\end{array}$ & $P$ value \\
\hline \multicolumn{5}{|c|}{$\begin{array}{c}\text { Do you think regular medications will } \\
\text { improve the disease? }\end{array}$} \\
\hline Yes & $114(95 \%)$ & $115(95.8 \%)$ & $0.8 \%$ & 0.475 \\
\hline No & $6(5 \%)$ & $5(4.2 \%)$ & $-0.8 \%$ & \\
\hline \multicolumn{5}{|c|}{$\begin{array}{c}\text { Do you think medications alone can } \\
\text { control hypertension? }\end{array}$} \\
\hline Yes & $57(47.5 \%)$ & $37(30.8 \%)$ & $-17.5 \%$ & $0.019^{*}$ \\
\hline No & $63(52.5 \%)$ & $83(69.2 \%)$ & $16.7 \%$ & \\
\hline \multicolumn{5}{|c|}{$\begin{array}{l}\text { Do you think diet control will improve } \\
\text { the condition? }\end{array}$} \\
\hline Yes & $49(40.8 \%)$ & $106(88.3 \%)$ & $47.5 \%$ & $<0.001^{* *}$ \\
\hline No & $71(59.2 \%)$ & $14(11.7 \%)$ & $-47.5 \%$ & \\
\hline \multicolumn{5}{|c|}{ Do you think salt reduction can control } \\
\hline hypertension? & & & & \\
\hline Yes & $64(53.3 \%)$ & $116(96.7 \%)$ & $43.4 \%$ & \\
\hline No & $56(46.7 \%)$ & $4(3.3 \%)$ & $-43.4 \%$ & $<0.001^{* *}$ \\
\hline \multicolumn{5}{|c|}{ Do you think regular physical activity is needed } \\
\hline Yes & $65(54.2 \%)$ & $116(96.7 \%)$ & $42.5 \%$ & $<0.001^{* *}$ \\
\hline No & $55(45.8 \%)$ & $4(3.3 \%)$ & $-42.5 \%$ & \\
\hline \multicolumn{5}{|l|}{ Reducing extra cooking oil } \\
\hline Yes & $60(50 \%)$ & $116(96.7 \%)$ & $46.7 \%$ & $<0.001^{* *}$ \\
\hline No & $60(50 \%)$ & $4(3.3 \%)$ & $-46.7 \%$ & \\
\hline
\end{tabular}


Table 5: Impact of patient counselling on Practice related questions $(n=120)$.

\begin{tabular}{|c|c|c|c|c|}
\hline $\begin{array}{c}\text { Practice related } \\
\text { questions }\end{array}$ & Pre-counselling & $\begin{array}{c}\text { Post } \\
\text { counselling }\end{array}$ & $\begin{array}{c}\% \\
\text { difference } \\
\end{array}$ & $P$ value \\
\hline \multicolumn{5}{|c|}{ Where was first diagnosed with hypertension? } \\
\hline Government & $19(15.8 \%)$ & $19(15.8 \%)$ & $0.0 \%$ & 0.500 \\
\hline Private & $101(84.2 \%)$ & $101(84.2 \%)$ & $0.0 \%$ & \\
\hline \multicolumn{5}{|l|}{ Regular follow up } \\
\hline Yes & $98(81.7 \%)$ & $116(96.7 \%)$ & $15.0 \%$ & 0.109 \\
\hline No & $22(18.3 \%)$ & $4(3.3 \%)$ & $-15.0 \%$ & \\
\hline \multicolumn{5}{|c|}{ Did you ever experience any side effects } \\
\hline Yes & $24(20 \%)$ & $30(25 \%)$ & $5.0 \%$ & 0.208 \\
\hline No & $96(80 \%)$ & $90(75 \%)$ & $-5.0 \%$ & \\
\hline \multicolumn{5}{|c|}{ Did you ever take double dose? } \\
\hline Yes & $18(15 \%)$ & $43(35.8 \%)$ & $20.8 \%$ & $0.001^{* *}$ \\
\hline No & $102(85 \%)$ & $77(64.2 \%)$ & $-20.8 \%$ & \\
\hline \multicolumn{5}{|c|}{ Are you avoiding extra salt } \\
\hline Yes & $80(66.7 \%)$ & $117(97.5 \%)$ & $30.8 \%$ & $0.004^{* *}$ \\
\hline No & $40(33.3 \%)$ & $3(2.5 \%)$ & $-30.8 \%$ & \\
\hline \multicolumn{5}{|c|}{ Are you doing any physical exercise daily? } \\
\hline Yes & $33(27.5 \%)$ & $118(98.3 \%)$ & $70.8 \%$ & $<0.001^{* *}$ \\
\hline No & $87(72.5 \%)$ & $2(1.7 \%)$ & $-70.8 \%$ & \\
\hline \multicolumn{5}{|c|}{ Are you taking your drugs regularly? } \\
\hline Yes & $82(68.3 \%)$ & $118(98.3 \%)$ & $30.0 \%$ & $0.005^{\star *}$ \\
\hline No & $38(31.7 \%)$ & $2(1.7 \%)$ & $-30.0 \%$ & \\
\hline
\end{tabular}

The above table shows that there was a great impact of counseling on the parameters and greater improvement were observed.

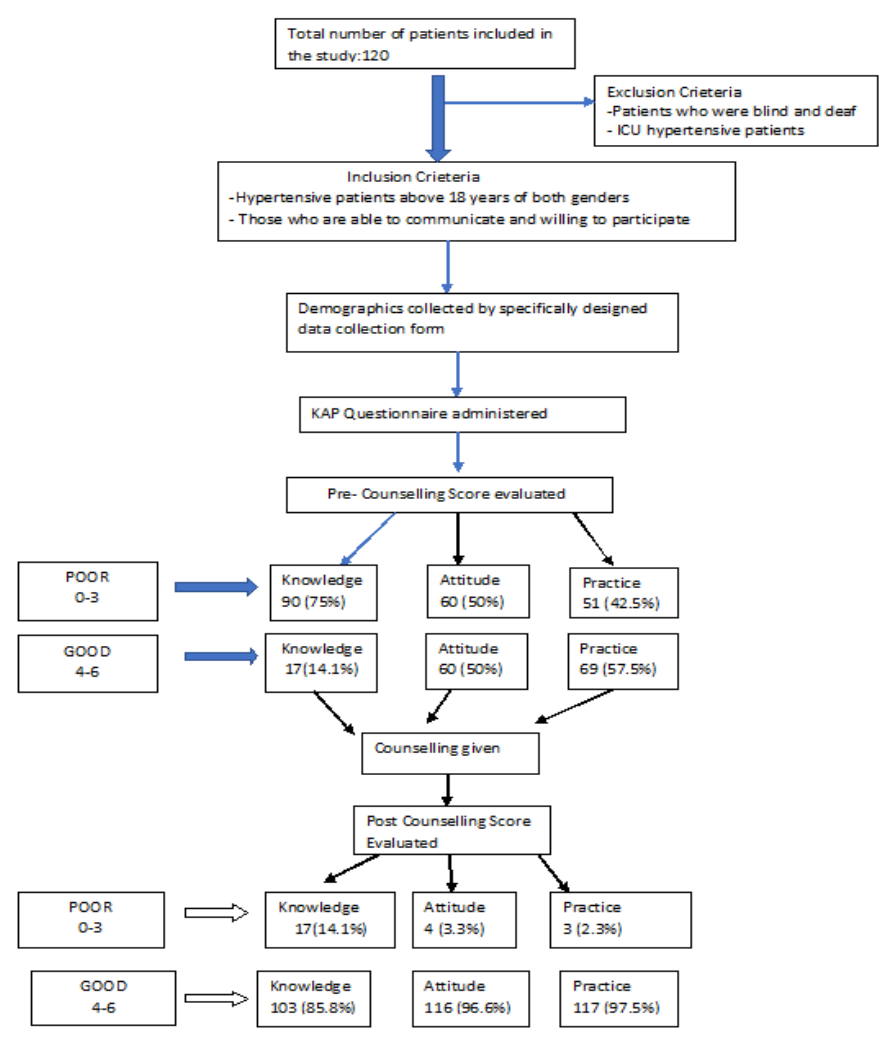

Figure 1: A schematic representation of study design and summary of results.
Many studies have manifested that blood pressure can be controlled with proper patient management. Our study shows that patient education has a major role in improving the health care outcomes in hypertensive patients. Our study demonstrates that pharmacist's interventions achieved significant improvement in KAP scores of the patients which eventually leads to reducing BP and improving quality of life of hypertensive patients.

\section{LIMITATIONS}

1. In this study there was no proper evidence about the complete follow up of patients.

2. The study was conducted for shorter duration of time.

3. Data with higher amount of authenticity can be obtained if other hospitals are also included in the study.

\section{CONCLUSION}

In our prospective interventional study, we reached to a conclusion that after counselling there was statistically significant improvement in patients' knowledge, attitude and practice regarding hypertension. We tried to improve the knowledge of patients suffering from HTN. Most of the patients were unaware about the complications of hypertension and lifestyle changes which showed the need of patient counselling. Our study concludes that hypertension affects the quality of life of patients and the education has a major role in improving the healthcare outcomes. Poor knowledge and practice can lead to worsening the health condition in time being and resulting in severe complications and damaging of other vital organs also. So proper educational strategies has to be adopted for patients. 


\section{ACKNOWLEDGEMENT}

We wish to express our sincere gratitude to all the people who participated and cooperated in our study.

\section{CONFLICT OF INTEREST}

The authors declare there is no conflict of interest

\section{Funding}

This research did not receive any specific grant from any funding agencies.

\section{ABBREVIATIONS}

CVD: Cardiovascular disease; SBP: Systolic Blood Pressure; DBP: Diastolic Blood Pressure; DASH: Dietary Approach to Stop Hypertension; KAP: Knowledge Attitude Practice.

\section{REFERENCES}

1. Lim SS, Vos T, Flaxman AD, Danaei G, Shibuya K, Adair-Rohani H, Amann M, et al. A comparative risk assessment of burden of disease and injury attributable to 67 risk factors and risk factor clusters in 21 regions, 1990-2010: A systematic analysis for the Global Burden of Disease Study 2010. Lancet. 2012;380(9859):2224-60. doi: 10.1016/S0140-6736(12)61766-8, PMID 23245609.

2. Kearney PM, Whelton M, Reynolds K, Muntner P, Whelton PK, He J. Global burden of hypertension: analysis of worldwide data. Lancet. 2005;365(9455):217-23. doi: 10.1016/S0140-6736(05)17741-1, PMID 15652604.

3. Gupta R. Trends in hypertension epidemiology in India. J Hum Hypertens. 2004;18(2):73-8. doi: 10.1038/sj.jhh.1001633.

4. Mackey J, Risk Factor MG. Blood pressure. In: Ann H, editor, The atlas of heart disease and stroke. 1st ed. Geneva: WHO; 2004. p. 28-30.

5. Lopez AD, Mathers CD, Ezzati M, Jamison DT, Murray CJ. Global burden of disease and risk factors [internet]. International bank for reconstruction and development; 2006. Global burden of disease and risk factors. The World Bank [cited 23/7/2021].

6. Buang NFB, Rahman NAA, Haque M. Knowledge, attitude and practice regarding hypertension among residents in a housing area in Selangor, Malaysia. Med Pharm Reports. 2019;92(2):145-52.

7. Hypertension Study Group. Prevalence, awareness, treatment and control of hypertension among the elderly in Bangladesh and India: a multicentre study. Bull World Health Organ. 2001;79(6):490-500. PMID 11436469.

8. Giles TD, Materson BJ, Cohn JN, Kostis JB. Definition and classification of hypertension: an update. J Clin Hypertens (Greenwich). 2009;11(11):611-14. doi: 10.1111/j.1751-7176.2009.00179.x, PMID 19878368.

9. High blood pressure (hypertension) - Symptoms and causes - Mayo Clinic. Available in https://www.mayoclinic.org/diseases-conditions/high-blood-pressure/ symptoms-causes/syc-20373410 [Last assessed on 6 Jul 2021].

10. Bell K. Candidate P, Olin BR. Hypertension: the Silent Killer: updated JNC-8 Guideline Recommendations. Available in https://cdn.ymaws.com/www.aparx. org/resource/resmgr/CEs/CE_Hypertension_The_Silent_K.pdf [Last assessed on 6 Jul 2021]

11. Ralapanawa U, Bopeththa K, Wickramasurendra N, Tennakoon S. Hypertension Knowledge, Attitude, and Practice in Adult Hypertensive Patients at a Tertiary Care Hospital in Sri Lanka. Int J Hypertens. 2020;2020:4642704. doi:
10.1155/2020/4642704. PMID 33145107.

12. Balraj M. Faruqui A. Efficacy and safety of triple drug fixed-dose combination of telmisartan, amlodipine and hydrochlorothiazide in the management of hypertension. Int J Res Med Sci. 2015;3(8):1858-62. doi: 10.18203/2320-6012. ijrms20150291.

13. Bollampally M, Chandershekhar P, Kumar K, Surakasula A, Srikanth S, Reddy T. Assessment of patient's knowledge, attitude and practice regarding hypertension. Int J Res Med Sci. 2016:4(8):3299-304. doi: 10.18203/2320-6012. ijrms20162283.

14. Seham A. Abd El-Hay, Samira E, el Mezayen. Knowledge and perceptions related to hypertension, lifestyle behavior modifications and challenges that facing hypertensive patients. IOSR JNHS. 2015;4(6):15-26.

15. Bollu M, Nalluri K, Prakash A, Lohith M, Venkataramarao N. Study of knowledge, attitude, and practice of general population of Guntur toward silent killer diseases: hypertension and diabetes. Asian J Pharm Clin Res. 2015;8(4):74-8.

16. Mahajan $\mathrm{H}$. Assessment of KAP, Risk factors and associated co-morbidities in hypertensive patients. IOSR-JDMS. 2012;1 (2):6-14. doi: 10.9790/0853-0120614

17. Kumar S, Mittal A, Bishnoi A. Study of knowledge, attitude and practice of genera population of Ambala towards hypertension. Int J Heal Sci Res. 2016;6(8):24.

18. Gradman AH, Basile JN, Carter BL, Bakris GL, American Society of Hypertension Writing Group. Combination therapy in hypertension. J Am Soc Hypertens. 2010;4(1):42-50. doi: 10.1016/j.jash.2010.02.005, PMID 20374950.

19. Macdonald TM, Williams B, Caulfield M, Cruickshank JK, Mcinnes G, Sever P, Webb DJ, Mackenzie IS, Salsbury J, Morant S, Ford I, Brown MJ. Monotherapy versus dual therapy for the initial treatment of hypertension (Pathway-1): a randomised double-blind controlled trial. BMJ Open. 2015;5(8):e007645. doi: 10.1136/bmjopen-2015-007645, PMID 26253566.

20. Shaikh M, Dur-e-Yakta KR. Hypertension knowledge, attitude and practice in adult hypertensive patients at LUMHS. JLUMHS. 2012;11(02):1136.

21. Siddiqua A, Mohammed A, Alahmari E, Hadaddi F, Saleh N. Study on the knowledge, attitude and practice of patients with hypertension in A seer hospital. Int J Res Pharm Sci. 2017;7(2):37-41.

22. Ramli A, Ahmad NS, Paraidathathu T. Medication adherence among hypertensive patients of primary health clinics in Malaysia. Patient Prefer Adherence. 2012;6:613-22. doi: 10.2147/PPA.S34704, PMID 22969292.

23. Chataut J, Adhikari RK Sinha NP. The prevalence of and risk factors for hypertension in adults living in central development region of Nepal. Kathmandu Univ Med J (KUMJ). 2011;9(33):13-8. doi: 10.3126/kumj.v9i1.6255, PMID 22610802.

24. Parmar P, Rathod G, Rathod S, Goyal R, Aggarwal S, Parikh A. Study of knowledge, attitude and practice of general population of Gandhinagar towards hypertension. Int J Curr Microbiol Appl Sci. 2014;3(8):680-85.

25. Naveen B, Mahaboojan M, Padmanabha YR, Narayana G. Impact of clinical pharmacist mediated patient counselling on health related quality of life in hypertensive patients. Indian J Pharm Pract. 2014;7(1):34-40.

26. Effect of pharmacist directed counselling services on Knowledge, Attitude, and Practice (KAP) and blood pressure control in hypertensive patients: A randomized control trial. Int J Pharm Sci Res. 2019;10(11):5109-16.

27. Mukamal KJ. The effects of smoking and drinking on cardiovascular disease and risk factors. Alcohol Res Health. 2006;29(3):199-202. PMID 17373409

28. Friedman GD, Klatsky AL, Siegelaub AB. Alcohol, tobacco, and hypertension Hypertension. 1982;4(5 Pt 2):II143-50. doi: 10.1161/01.hyp.4.5_pt_2.iii143, PMID 7049929

29. Wu X, Wang Z. Role of socioeconomic status in hypertension among Chinese middle-aged and elderly individuals. Int J Hypertens. 2019;2019:Article ID 6956023. doi: 10.1155/2019/6956023, PMID 31737361.

30. Leng B, JinY, Li G, Chen L, Jin N. Socioeconomic status and hypertension: a metaanalysis. J Hypertens. 2015;33(2):221-9. doi: 10.1097/HJH.0000000000000428, PMID 25479029 